\title{
Effects of climate change on the distribution of wild Akebia trifoliata
}

\author{
Jun-Ming Zhang ${ }^{1}$, Xiang-Yong Peng ${ }^{2}$, Min-Li Song ${ }^{3}$, Zhen-Jian Li ${ }^{1}$, Xin-Qiao Xu' ${ }^{1}$, and \\ Wei Wang ${ }^{1}$ \\ ${ }^{1}$ Chinese Academy of Forestry \\ ${ }^{2}$ Qufu Normal University \\ ${ }^{3}$ Taiyuan Normal University
}

September 25, 2021

\begin{abstract}
Understanding the impacts and constraints of climate change on the potential geographic distribution of wild Akebia trifoliata is crucial for its sustainable management and economic development as a medicinal material or fruit. In this study, according to the first-hand information obtained on-the-spot investigation, the geographic distribution and response to climate factors of Akebia trifoliata were studied by the MaxEnt model and ArcGIS. The genetic diversity and population structure of 21 natural populations of Akebia trifoliata were studied by SSR markers. The results showed that precipitation and temperature were the two most important climatic factors that restrict the geographic distribution of Akebia trifoliata. Under the current climate scenario, the suitable growth regions of Akebia trifoliata in China were 91.7-121.9 ${ }^{\circ} \mathrm{E}$ and $21.6-37.5^{\circ} \mathrm{N}$. Combined with the evolutionary relationship and prediction results, 21 populations of Akebia trifoliata tended to migrate to the north. In the scenarios (SSP2-4.5, SSP3-7.0, and SSP5-8.5) of higher greenhouse gas emission concentration, the distribution area of Akebia trifoliata continued to expand, while in the low concentration greenhouse gas emission scenario (SSP1-2.6), the distribution area of Akebia trifoliata remained stable. The distribution center of Akebia trifoliata in China will shift to high latitude regions with the increase of temperature in the future. The results evaluated the impact of climate factors on the spatial distribution of wild Akebia trifoliata, displayed the possible changes of geographical distribution of Akebia trifoliata under different climate scenarios, and provided scientific evidence for durative protection and supervise of Akebia trifoliata.
\end{abstract}

\section{Hosted file}

manuscript0823. doc available at https : //authorea.com/users/436130/articles/538677-effects-ofclimate-change-on-the-distribution-of-wild-akebia-trifoliata 


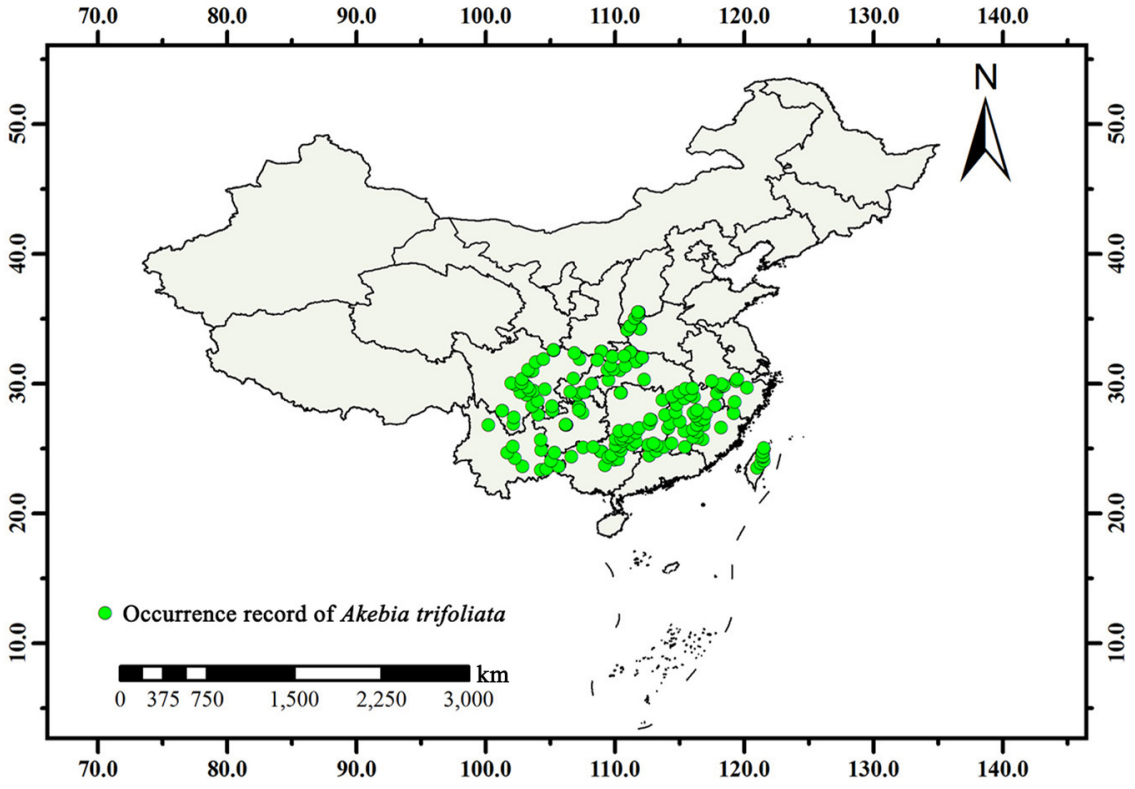


A

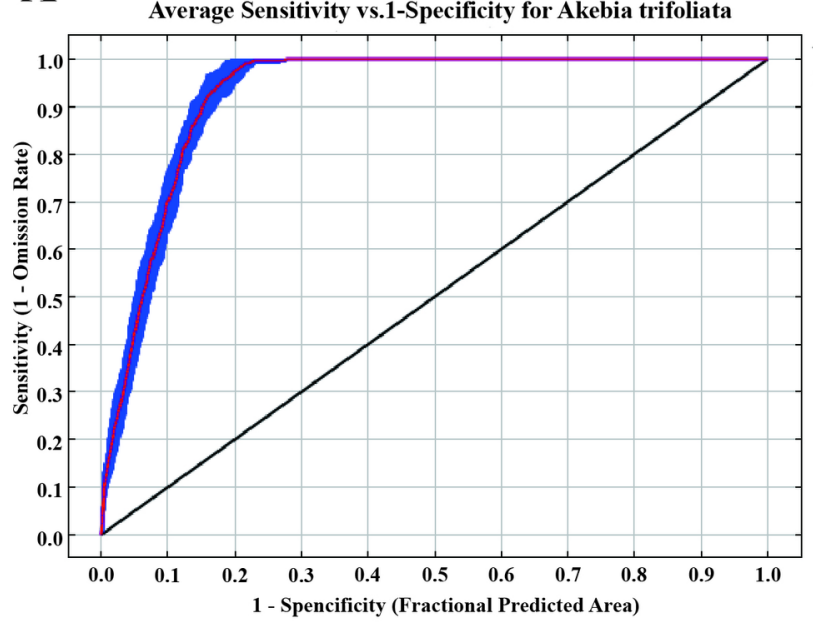

Mean $(A U C=0.928)=$

Mean $+/$ - one stddev

Random Prediction -

B

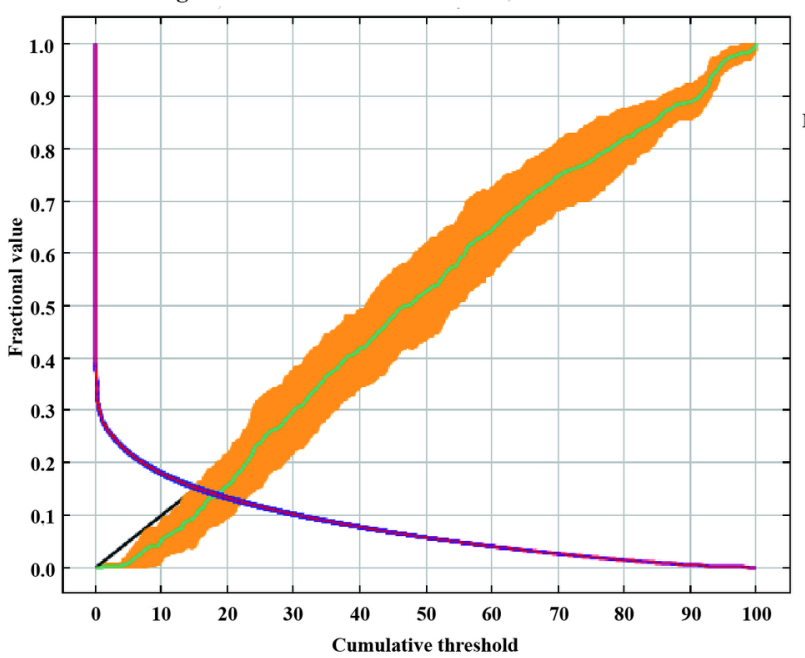

Mean area $"$

Mean area $+/$ - one stddev =

Mean omission on test data = Mean omission $+/$ - one stddev " Predicted omission -

\section{C}

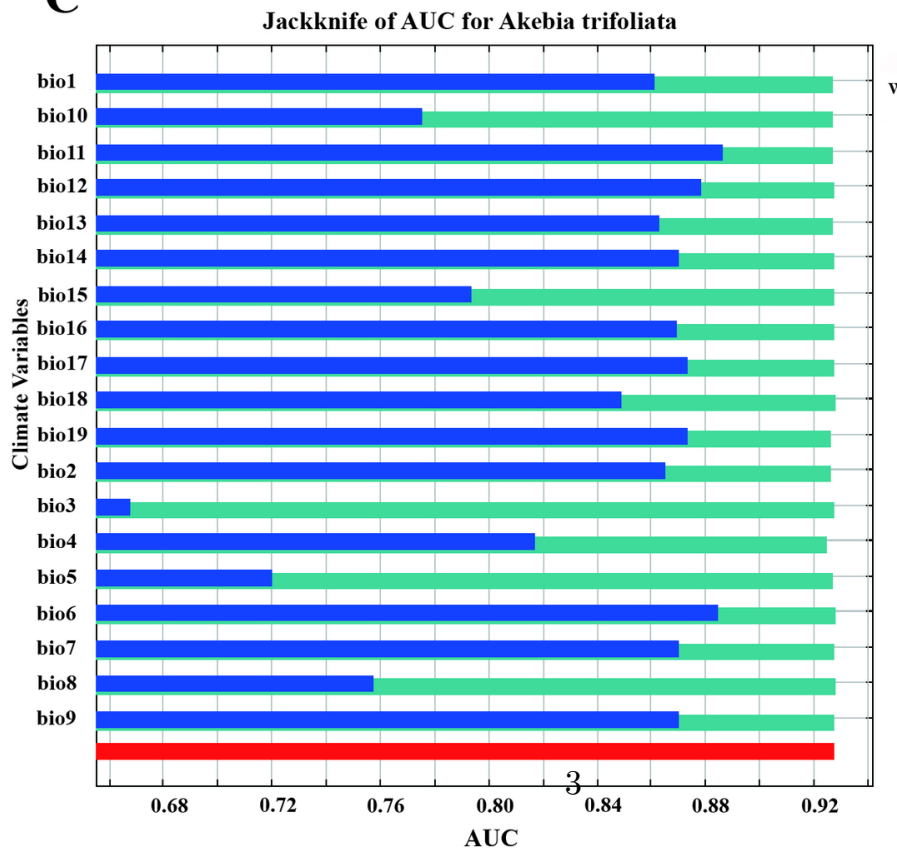

Without variables. With only variables With all variables 

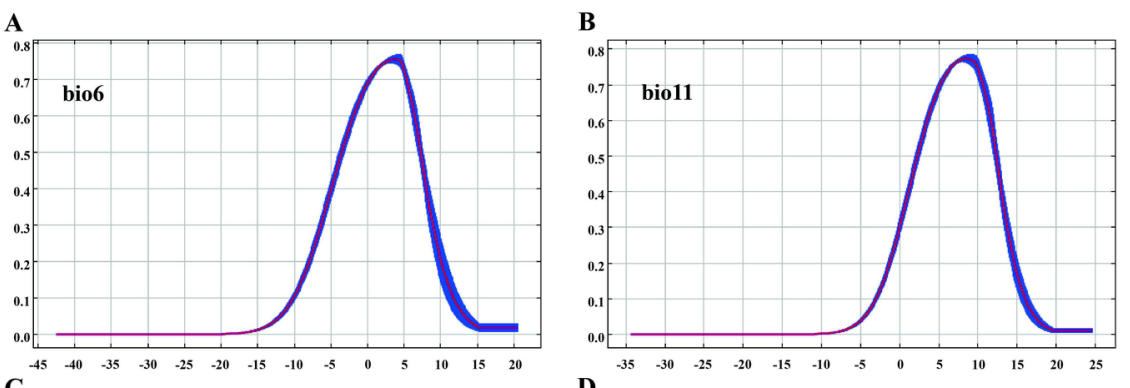

C

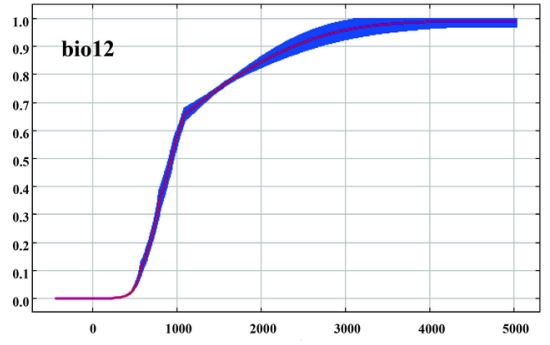

D
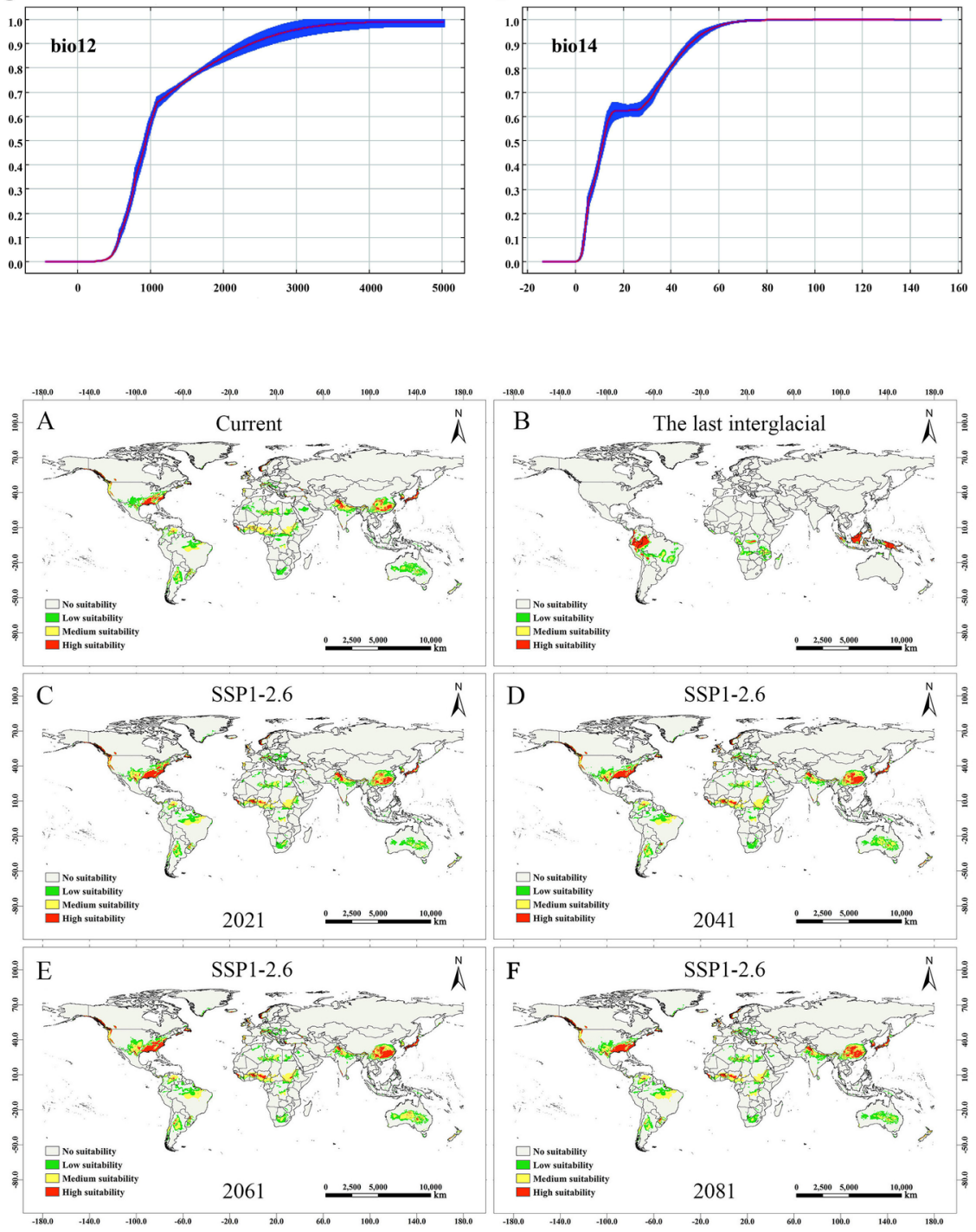


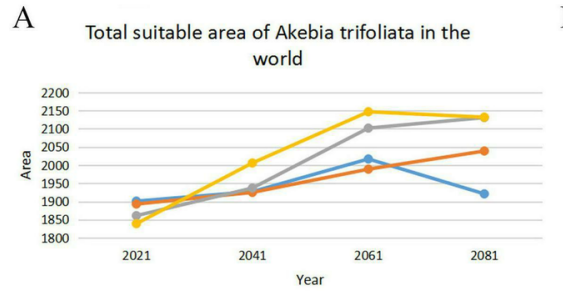

$\multimap$ SSP1-2.6 $\rightarrow$ SSP2-4.5 $\rightarrow$ SSP3-7.0 $\multimap-$ SSP5-8.5

C

High suitable area of Akebia trifoliata in the world

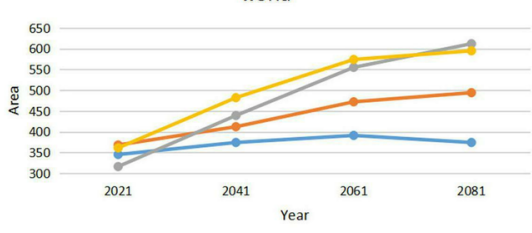

$\rightarrow$ SSP1-2.6 $\rightarrow$ SSP2-4.5 $\rightarrow$ SSP3-7.0 $\rightarrow-$ SSP5-8.5

A

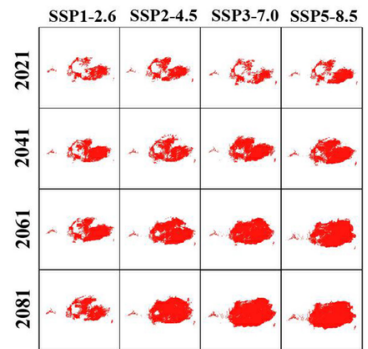

C

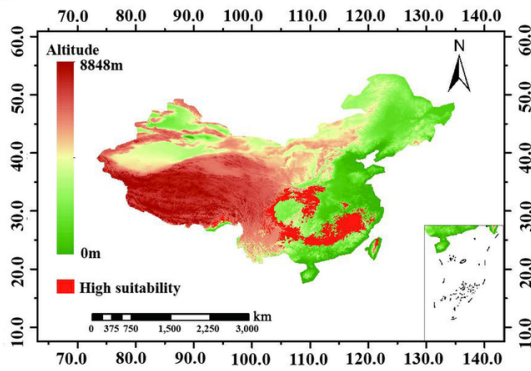

B

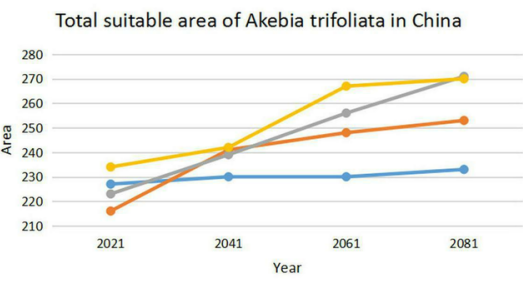

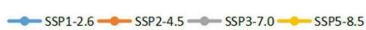

D

High suitable area of Akebia trifoliata in China

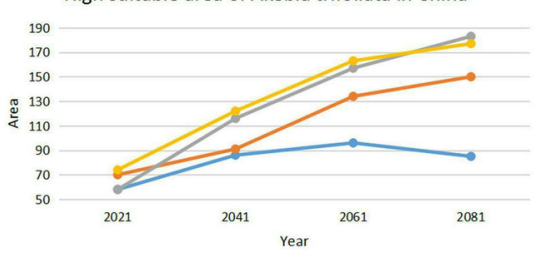

$\rightarrow$ SSP1-2.6 $\rightarrow$ SSP2-4.5 $\rightarrow$ SSP3-7.0 $\rightarrow-$ SSP5-8.5

B

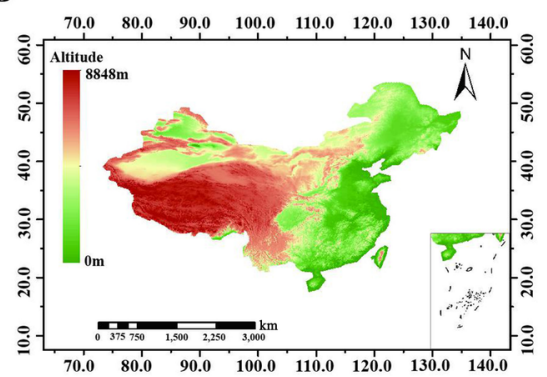

D

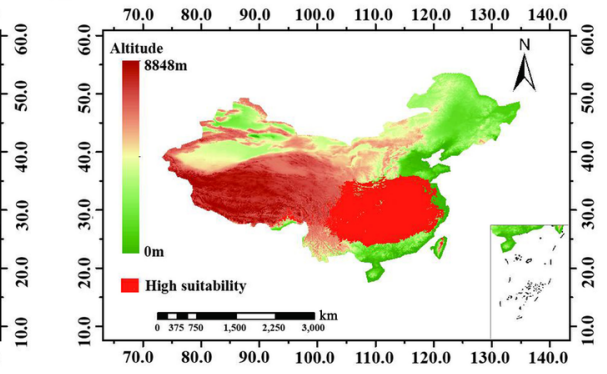



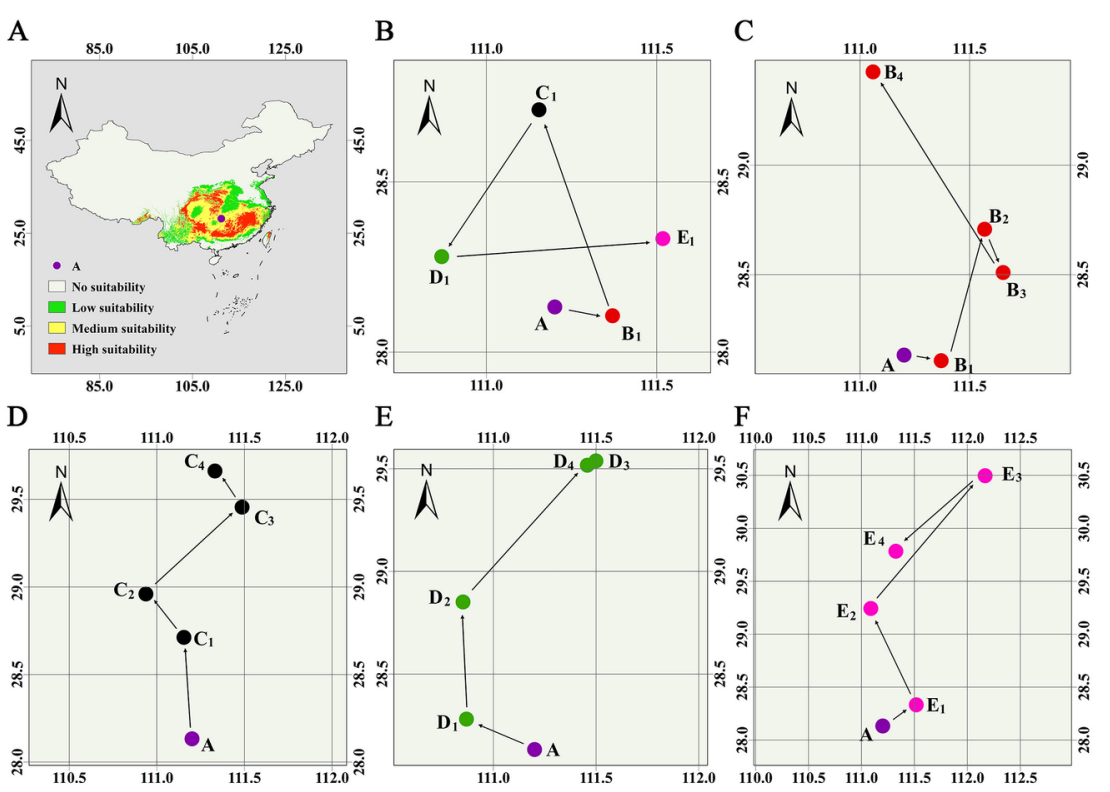

A

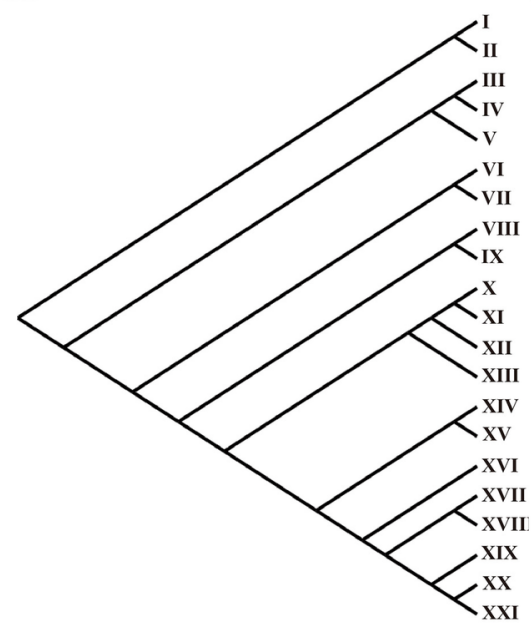

B

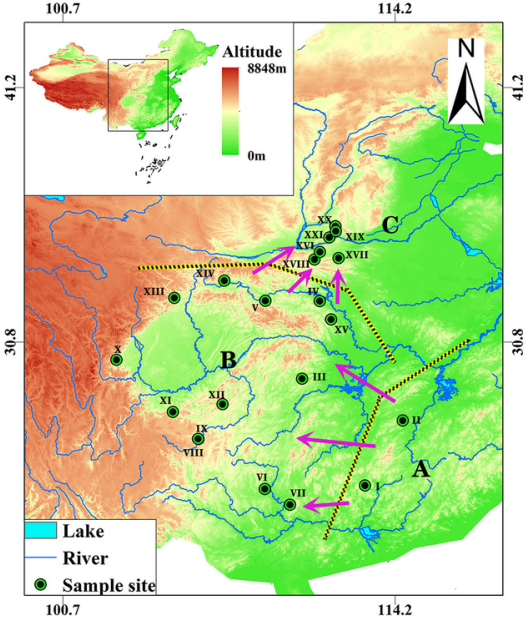

